\section{Matéria}

ISSN 1517-7076
Revista Matéria, v. 12, n. 1, pp. 215 - 225, 2007

http://www.materia.coppe.ufrj.br/sarra/artigos/artigo10877

\title{
Recuperação de Cobalto de Baterias de Níquel Metal-Hidreto (Ni-MH) via Extração Seletiva com Cyanex 272
}

\author{
${ }^{1}$ Ana Paula Mauro Gonçalves Barandas, 'Júlio Carlos Afonso, \\ ${ }^{2}$ José Luiz Mantovano e ${ }^{2}$ José Waldemar Silva Dias da Cunha \\ ${ }^{1}$ Departamento de Química Analítica \\ Instituto de Química, Universidade Federal do Rio de Janeiro. \\ C P 68563. Ilha do Fundão, Rio de Janeiro, RJ. CEP:21949-900 \\ e-mail: barandas@terra.com.br,julio@iq.ufrj.br \\ ${ }^{2}$ Divisão de Química e Materiais Nucleares \\ Instituto de Engenharia Nuclear \\ C P 68550. Ilha do Fundão, Rio de Janeiro, RJ. CEP:21945-970 \\ e-mail: mantovan@ien.gov.br, jwcunha@ien.gov.br
}

\begin{abstract}
RESUMO
A extração de metais com solventes orgânicos é uma poderosa ferramenta para ajudar a separação de complexas misturas de metais presentes em baterias usadas e dispositivos eletroeletrônicos, evitando assim o uso de produtos tóxicos ou de rotas experimentais geradoras de uma grande quantidade de resíduos finais. Este trabalho descreve um processo de recuperação de cobalto presente em baterias níquel metalhidreto $(\mathrm{Ni}-\mathrm{MH})$ usadas por meio de uma nova rota hidrometalúrgica. O elemento foi extraído de uma solução em meio clorídrico com Cyanex 272 (ácido 2,4,4-trimetil-pentil fosfínico) dissolvido em querosene. Os melhores resultados foram obtidos quando o $\mathrm{pH}$ estava ligeiramente alcalino $(7,2)$ e a concentração de Cyanex em querosene era $5 \%$ vol. A recuperação do cobalto atingiu $99 \% \mathrm{~m} / \mathrm{m}$. Foi também possível recuperar um precipitado contendo lantanídios (La, Ce, Pr) e ítrio, que foi purificado pela dissolução em ácido clorídrico seguido de adição de oxalato de amônio. O níquel também foi isolado como um precipitado impuro após a recuperação do cobalto e dos lantanídios. Os residuos finais gerados ao longo do processo são principalmente soluções de cloreto de sódio, sem coloração, turbidez ou metais pesados em quantidades significativas.
\end{abstract}

Palavras chaves: Cobalto, cyanex 272, baterias Ni-MH.

\section{Recovery of Cobalt From Nickel Metal-Hydride (Ni-MH) Batteries Via Selective Extraction With Cyanex 272}

\begin{abstract}
Metals extraction with organic solvents is a powerful tool to aid separation of complex mixtures of elements present in spent batteries and electronic devices, thus avoiding the use of toxic chemicals or experimental routes which generate high amounts of final wastes. This work describes a recovery process for cobalt present in spent Ni-MH batteries by a new hydrometallurgical route. The element was extracted in a chloride-bearing medium with Cyanex 272 (2,4,4-trimethyl-pentyl fosfinic acid) dissolved in kerosene. The best results were obtained when $\mathrm{pH}$ was slightly alkaline $(7,2)$ and Cyanex concentration in kerosene was $5 \%$ vol. Cobalt recovery reached $99 \mathrm{wt} \%$. It was also possible to recover a crude precipitate containing lanthanides (La, Ce, Pr) and yttrium, which was purified by dissolving it in $\mathrm{HCl}$ followed by addition of ammonium oxalate. Nickel was also isolated as an impure precipitate after cobalt and lanthanides recoveries. Final wastes generated along the separation processes are mainly sodium chloride solutions with no color, turbidity or heavy metals present in significant amounts.
\end{abstract}

Keywords: Cobalt, cyanex 272, Ni-MH batteries. 


\section{INTRODUÇÃO}

A tecnologia da bateria de níquel metal-hidreto (Ni-MH) data do final da década de 1980, e a comercialização teve início no Japão em 1990 [1]. Elas são propostas como substitutas das baterias de níquelcádmio (Ni-Cd) para algumas de suas aplicações, principalmente em equipamentos portáteis (computadores e celulares, por exemplo), face às seguintes vantagens $[\underline{1}, \underline{2}]$ : maior capacidade de carga, maior número de ciclos de carga-descarga $(500$ a 1000$)$, ampla temperatura de operação $\left(-20 /+60{ }^{\circ} \mathrm{C}\right)$, baixa taxa de autodescarga, efeito memória praticamente inexistente e menor dano ambiental pela ausência do cádmio.

Para a formação da liga níquel-metal, que faz o papel do cádmio na bateria de Ni-Cd, parte-se do composto intermetálico $\mathrm{AB}_{5}$, onde $\mathrm{A}$ é um elemento da série lantanídia (lantânio, por exemplo) e $\mathrm{B}$ é o níquel; essa liga tem a capacidade de estocar hidrogênio gerado na decomposição da água, liberando-o na reação inversa de geração desse composto. O lantânio é comumente substituído por uma liga de níquel contendo lantânio, cério, praseodímio, neodímio e samário, conhecida comercialmente como mischmetal [3]].

Deve-se considerar que a substituição da bateria de Ni-Cd por outras tecnologias se dará de forma gradual, tempo em que as baterias de Ni-MH (e íons lítio) evoluirão sob o ponto de vista tecnológico, principalmente para enfrentar o desafio da substituição dos modelos de emprego industrial [4].

As reações químicas que ocorrem na bateria de Ni-MH são $[\underline{5}, \underline{6}]$ :

No eletrodo positivo (catodo):

$$
\mathrm{Ni}(\mathrm{OH})_{2}+\mathrm{OH}^{-} \underset{\text { carga }}{\stackrel{\text { descarga }}{\longleftarrow}} \mathrm{NiOOH}+\mathrm{H}_{2} \mathrm{O}+\mathrm{e}^{-}
$$

No eletrodo negativo (anodo):

$$
\mathrm{e}^{-}+(1 / \mathrm{n}) \mathrm{M}+\mathrm{H}_{2} \mathrm{O} \underset{\text { carga }}{\stackrel{\text { descarga }}{\longrightarrow}}\left(1 / \mathrm{n}^{2} \mathrm{MH}_{\mathrm{n}}+\mathrm{OH}^{-}\right.
$$

A reação total da bateria é:

$$
\mathrm{Ni}(\mathrm{OH})_{2}+1 / \mathrm{n} \mathrm{M} \underset{\text { carga }}{\stackrel{\text { descarga }}{\rightleftarrows}} \mathrm{NiOOH}+(1 / \mathrm{n}) \mathrm{MH}_{\mathrm{n}}
$$

A literatura registra que numa bateria de Ni-MH, além do níquel, já foi relatada a presença de alumínio, cério, cobalto, cromo, ferro, lantânio, manganês, titânio, vanádio, zinco, zircônio, potássio, neodímio e praseodímio [7]. Ferro, manganês e alumínio são encontrados no anodo, enquanto que cobalto e zinco no catodo [1]. O eletrólito básico é composto por $\mathrm{KOH}$ [2].

Apesar do custo mais elevado da bateria de Ni-MH em relação à de Ni-Cd []], dados de 1999 [9] fornecidos pela entidade representativa do setor produtivo de pilhas e baterias ("European Portable Battery Association" - EPBA) indicam que na Europa o mercado das baterias de Ni-MH representou cerca de $25 \%$ (5.200 ton) do total comercializado de modelos portáteis recarregáveis, percentual esse de $35 \%$ em 2003. Em $2000,50 \%$ do mercado japonês de energia portátil era da bateria de Ni-MH [1]. O carro elétrico e a versatilidade de formatos possíveis abrem a perspectiva de um mercado em franco crescimento para essas baterias (e as de íons-lítio) [1] $]$. Isso leva à conclusão de que a geração de baterias usadas desse tipo crescerá muito nos próximos anos, o que significa um potencial de reciclagem atrativo devido à presença de elementos de valor agregado considerável (cobalto, lantanídios) no produto $[1, \underline{2}, 11]$. Basta citar que a manufatura de baterias responde pela segunda maior aplicação comercial do cobalto $(11 \%)$, superado apenas pela fabricação de ligas [12].

Além do aspecto da reciclagem do produto usado, motivada por fatores econômicos, é preciso enfocar a questão ambiental referente à bateria de Ni-MH: apesar da remoção do cádmio de sua formulação, ela ainda contém o níquel, cujos compostos são reconhecidamente cancerígenos ao homem [13, 14], o que implica que, a rigor, essas baterias precisam ter uma destinação final adequada ou então recicladas [10], ao contrário do que afirma a indústria do setor [4], e mesmo artigos da literatura $[1,10]$.

As pilhas e baterias usadas são motivo de preocupações ambientais. O caráter perigoso desses produtos está associado à presença de elementos altamente tóxicos aos seres vivos (cádmio, mercúrio e níquel, dentre outros) em sua formulação. $\mathrm{O}$ descarte do produto sem critério significa um elevado risco de contato de seus componentes com o meio ambiente. Uma ameaça é a possibilidade de contaminação das águas subterrâneas, que é função do local de disposição dos produtos usados e de sua proximidade com os lençóis freáticos. A rigor, o ideal é que nenhuma pilha ou bateria tenha o mesmo destino do lixo urbano, ou 
seja, que não sejam aterradas, submetidas à compostagem ou incineradas. A alternativa para a remoção do lixo doméstico passa pela coleta seletiva [14].

A situação da legislação e da estrutura do setor produtivo no Brasil, em relação à gestão de pilhas e baterias esgotadas, está consideravelmente avançada, em relação a outros países da América Latina e do Caribe, mas ainda está distante das nações onde os princípios e instrumentos sócio-ambientais e econômicos são mais desenvolvidos [15]. Por exemplo, no Estado do Rio de Janeiro, em 2000, foi sancionada a Lei 3.415 [16], regulamentando o serviço de coleta e descarte final para pilhas e baterias, equiparando-as a lixo químico.

Na Europa e nos Estados Unidos não há consenso, quanto à conduta a ser adotada para pilhas e baterias que não estejam previstas nas resoluções ambientais ( $\mathrm{Ni}-\mathrm{Cd}, \mathrm{Pb}$-ácido, $\mathrm{Hg}$ ) [모, $\underline{15}]$. Para uns, esses produtos usados podem ser "jogados no lixo" (pilhas alcalinas, $\mathrm{Zn} /$ carvão, $\mathrm{Li} / \mathrm{MnO}_{2}$ e baterias de Ni-MH e íons-lítio) [15]. Em determinados estados norte-americanos, entretanto, a legislação é mais rígida, com base em bioensaios de toxicidade e as mesmas baterias acabam por serem definidas como resíduos perigosos [므, 15]. Alguns países adotam práticas temporárias. O Japão imobiliza baterias usadas em concreto e a Suécia as estoca em aterros especiais, até que as tecnologias de reciclagem sejam viáveis. A Itália manda os resíduos para aterro na França [15].

De um modo geral, os processos de reciclagem de pilhas e baterias podem seguir três linhas distintas: a baseada em operações de tratamento de minérios, a hidrometalúrgica ou a pirometalúrgica. Processos pirometalúrgicos não são adequados para as baterias de Ni-MH por não conterem elementos facilmente separáveis por destilação, e também porque levaria à perda total dos lantanídios no resíduo sólido de processo. Já os procedimentos hidrometalúrgicos têm a flexibilidade necessária para tal, mas exigem etapas de abertura e de separação mecânica/manual dos invólucros (plástico e aço) para a viabilidade do processo. O ferro atrapalha a separação dos elementos constituintes do catodo/anodo e aumenta o consumo de reagente [11]. Devido a isso existem propostas de remoção prévia desse elemento por meio de extração por solventes orgânicos após tratamento do material em meio $\mathrm{HCl} / \mathrm{HNO}_{3}$ [17] (mas não em $\mathrm{H}_{2} \mathrm{SO}_{4}$, pois a seletividade na extração de ferro é perdida).

A literatura é relativamente escassa em informações sobre processos hidrometalúrgicos para tratamento de baterias de Ni-MH, mas todos os processos descritos sempre empregam a abertura em meio ácido. O que varia é o modo de manipulação dos componentes internos da bateria (separação ou não em subfrações) e o modo de processar a solução obtida para a recuperação dos elementos presentes (ordem de recuperação dos mesmos) $[2,10,11]$. As diferenças de composição entre as baterias Ni-Cd e Ni-MH fazem com que seja desejável o processamento em separado para não perturbar a eficiência de fracionamento dos componentes de cada um dos produtos $[\underline{8}, \underline{19}]$.

Os ácidos empregados são o clorídrico $[\underline{1}, \underline{17}, \underline{20}, \underline{21}]$ ou o sulfúrico $[\underline{2}, \underline{10}, \underline{18}]$. O cobalto pode ser separado do níquel por técnicas de extração com solventes sob condições apropriadas [1, $\underline{10}, \underline{18}]$ ou por precipitação seletiva $[\underline{20}, \underline{21}]$. A literatura cita trabalhos onde a separação do cobalto de níquel é bastante eficiente com EHPA (ácido etil-hexil fosfórico), D2EHPA (ácido bis-2-etil-hexil fosfórico) e Cyanex 272 (ácido 2,4,4-trimetil-pentil fosfinico) em meio sulfúrico [10, 18, 22]. Em meio clorídrico o D2EHPA é citado [1] como capaz de remover o cobalto.

As baterias de Ni-MH contém metais das chamadas terras raras (TR), particularmente os lantanídios. É possível obter um processo de separação seletiva desses metais por precipitação seletiva usando $\mathrm{NaOH}$ para ajuste de $\mathrm{pH}$ e ácido sulfúrico para precipitação. Os TR precipitam [2, 23] na forma de $\operatorname{NaTR}\left(\mathrm{SO}_{4}\right)_{2}$. Outro método é a precipitação dos fosfatos $\mathrm{TRPO}_{4} \mathrm{em} \mathrm{pH} \mathrm{1,} \mathrm{em} \mathrm{meio} \mathrm{clorídrico} \mathrm{[20,} \mathrm{21]} \mathrm{(em}$ meio sulfúrico ocorre a co-precipitação de sulfatos e fosfatos). Ainda há a alternativa de extraí-los com extratantes (D2EHPA em HCl [1] ou $\mathrm{H}_{2} \mathrm{SO}_{4}$ [10]) em pH entre 0 e 1 (onde o níquel e o cobalto não são extraídos [10]), e a precipitação direta como oxalatos [21]. Este último método é comumente empregado para a obtenção de produtos finais contendo as TR com elevada pureza.

Este trabalho descreve um estudo de processamento de baterias de Ni-MH usadas em uma nova rota hidrometalúrgica de abertura, visando recuperar os elementos de valor agregado presentes nesse produto (cobalto e lantanídios). Foi testado o desempenho dos extratantes EHPA, D2EHPA e Cyanex 272 para a extração de cobalto em meio clorídrico, face ao bom desempenho deles em meio sulfúrico. Os lantanídios e o níquel foram isolados por técnicas de precipitação seletiva, seguido ou não de purificação do produto bruto. Fez-se também um controle analítico dos resíduos produzidos a fim de adequar os processos desenvolvidos às normas ambientais vigentes.

\section{PARTE EXPERIMENTAL}




\subsection{Matérias-primas}

Empregaram-se 120 baterias de Ni-MH de telefone celular usadas, todas de formato prismático, de quatro fornecedores diferentes, e fabricadas em 2002/2003 (marcas A e B) e 1999/2001 (marcas C e D). Todas elas foram abertas manualmente: os invólucros externos de plástico foram removidos; a seguir, a blindagem de aço foi removida, expondo os componentes internos, a saber: catodo, anodo, pasta eletrolítica, separador anodo-catodo (feito de material polimérico), e tela metálica de níquel. Todos os componentes foram pesados em balança analítica. Os elementos internos foram levados ao processo de dissolução.

\subsection{Processo de Dissolução}

A abertura ácida foi a metodologia escolhida porque é o meio universal de tratamento prévio das baterias usadas por via hidrometalúrgica, e também porque a grande maioria das etapas posteriores de fracionamento, independente da natureza, é realizada em meio ácido. Empregou-se ácido clorídrico concentrado $\left(12 \mathrm{~mol} \mathrm{~L}^{-1}\right)$, grau PA, sem purificação. Os experimentos foram conduzidos sob agitação manual, em capela sob exaustão. Os parâmetros operacionais estabelecidos foram: temperatura, $40{ }^{\circ} \mathrm{C}$; razão mássica (pasta eletrolítica + catodo + anodo + separador polimérico + tela metálica)/ácido clorídrico, $150 \mathrm{~g}$ $\mathrm{L}^{-1}$. Após a abertura, o separador, único componente insolúvel, foi isolado. $\mathrm{O}$ tempo de dissolução se completou em cerca de $30 \mathrm{~min}$, com exceção da tela metálica que, para dissolução completa, foram necessários cerca de $12 \mathrm{~h}$, obtendo-se uma solução de coloração verde devida ao $\mathrm{Ni}^{2+}$ presente.

\subsection{Extração de Cobalto (Separação do Níquel)}

A acidez livre foi determinada por titulação de neutralização direta [24] com $\mathrm{NaOH} 1 \mathrm{~mol} \mathrm{~L}^{-1}$, empregando um peagâmetro digital (eletrodo de referência $\mathrm{Ag} / \mathrm{AgCl}$ ).

Os experimentos foram conduzidos utilizando os seguintes extratantes: D2EHPA, EHPA e Cyanex 272 em diversas concentrações em querosene desodorizado $(5,10,20,30,40$, e $50 \%$ vol/vol). Todos os extratantes foram utilizados sem nenhuma purificação suplementar. $\mathrm{O}$ ajuste do $\mathrm{pH}$ da solução ácida foi feito com NaOH $6 \mathrm{~mol} \mathrm{~L}^{-1}$ (para pH 2, 3 e 5) ou com $\left(\mathrm{NH}_{4}\right)_{2} \mathrm{CO}_{3}$ sólido (para pH 7,2). A extração foi realizada em funil de separação empregando uma razão fase aquosa/fase orgânica (FA/FO) igual a 1 (vol/vol). O tempo de extração foi estipulado em 3 min, sob agitação manual, tempo suficiente para o estabelecimento do equilíbrio de extração. As fases se separaram completamente em $10 \mathrm{~min}$. Cada procedimento de extração foi executado em triplicata. A reextração do cobalto para a fase aquosa foi feita mediante o emprego de $\mathrm{HCl}$ concentrado (1:1 vol/vol) em um estágio. O metal precipitou após neutralização dessa solução com $\mathrm{NaOH} 6 \mathrm{~mol} \mathrm{~L}^{-1}$.

\subsection{Isolamento dos Lantanídios}

Esses elementos foram precipitados no ajuste do $\mathrm{pH}$ a 5 ou 7,2. O precipitado, de coloração verde claro, foi isolado antes da extração do cobalto. Ele foi dissolvido em $\mathrm{HCl} 6 \mathrm{~mol} \mathrm{~L}^{-1}$ de modo que a acidez livre se situasse entre 1 e $2 \mathrm{~mol} \mathrm{~L}^{-1}$; a subseqüente adição de $\left(\mathrm{NH}_{4}\right)_{2} \mathrm{C}_{2} \mathrm{O}_{4} 0,3 \mathrm{~mol} \mathrm{~L}^{-1}$ permitiu a precipitação em conjunto dos lantanídios, na forma de uma massa fina e levemente esverdeada [25]. O processo é mais bem conduzido a quente $\left(50-60^{\circ} \mathrm{C}\right.$ ) para coagular o precipitado, que pode ser filtrado e lavado (com solução de $\left.\left(\mathrm{NH}_{4}\right)_{2} \mathrm{C}_{2} \mathrm{O}_{4} 0,01 \mathrm{~mol} \mathrm{~L}^{-1}\right)$ em papel de filtro e seco em estufa a $105^{\circ} \mathrm{C}$ durante $1 \mathrm{~h}[\underline{24}, \underline{25}]$.

\subsection{Isolamento do Níquel}

O níquel e demais metais eventualmente presentes no rafinado foram precipitados por adição de $\mathrm{NaOH} 6 \mathrm{~mol} \mathrm{~L}^{-1}$ até $\mathrm{pH}$ em torno de 8-9.

\subsection{Métodos Analíticos}

A dosagem dos elementos presentes foi feita por fluorescência de raios-x (FRX). O aparelho utilizado foi o S4 - Explorer - Bruker - AXS (tubo $1 \mathrm{KeV}$ de ródio). Curvas de calibração foram estabelecidas ( $\mathrm{Ni}, \mathrm{Co}, \mathrm{La}$ e $\mathrm{Ce}$ ) onde as concentrações das soluções-padrão variaram de 0,1 a $10 \mathrm{~g} \mathrm{~L}^{-1}$. Todas as amostras foram pipetadas em papéis de filtro de mesmo diâmetro $(3,8 \mathrm{~cm})$ por meio de pipetas calibradas utilizando sempre o mesmo volume de amostra $(200 \mu \mathrm{L})$. 


\section{RESULTADOS E DISCUSSÃO}

\subsection{Composição das Baterias}

A Tabela 1 ilustra os resultados de percentual em massa de todos os componentes (invólucro de plástico, blindagem e elementos internos). Pode-se observar que há algumas diferenças entre as composições das baterias fabricadas mais recentemente (A e B) e as mais antigas (marcas C e D), o que configura uma certa discordância com estudos prévios da literatura [19]. Os componentes internos desses modelos mais recentes têm participação menor, enquanto que o invólucro de aço tem comportamento inverso. Uma possível explicação seria uma mudança de tecnologia de fabricação dessas baterias mais recentes, que incorporam menos componentes na formulação do catodo, do anodo e da pasta eletrolítica.

Tabela 1: Composição aproximada $(\% \mathrm{~m} / \mathrm{m})$ das baterias de Ni-MH estudadas* .

\begin{tabular}{cccc}
\hline Marca & $\begin{array}{c}\text { \% de invólucro } \\
\text { plástico }\end{array}$ & $\begin{array}{c}\text { \% blindagem } \\
(\text { aço })\end{array}$ & $\begin{array}{c}\text { \% componentes internos (catodo + anodo + pasta } \\
\text { eletrolítica + separador + tela de Ni) }\end{array}$ \\
\hline A & $21,2 \pm 2,7$ & $50,4 \pm 1,7$ & $28,4 \pm 1,9$ \\
B & $30,8 \pm 0,5$ & $43,8 \pm 0,4$ & $25,4 \pm 1,0$ \\
C & $24,4 \pm 4,5$ & $40,6 \pm 2,8$ & $35,0 \pm 2,7$ \\
D & $26,6 \pm 0,6$ & $32,9 \pm 0,3$ & $40,5 \pm 0,9$ \\
\hline
\end{tabular}

* valores expressos em intervalo de confiança a $95 \%$

\subsection{Elementos Presentes}

A Tabela 2 mostra os teores medidos de Ni e Co nas baterias analisadas. A variação nas quantidades de Ni e de Co não foi muito grande segundo a marca considerada. Porém, um fato deve ser chamado à atenção: com base nos valores relatados na literatura para o teor de níquel nas baterias de Ni-MH, pode-se observar que o valor máximo, $30 \% \mathrm{~m} / \mathrm{m}$, não é mais alcançado pelas amostras estudadas, e em muitos casos os valores encontrados situam-se ao nível do mínimo historicamente reportado na literatura $(10 \% \mathrm{~m} / \mathrm{m})[\underline{15}]$. Ao que tudo indica, nas novas tecnologias, a quantidade de níquel presente nas baterias tende a diminuir, sem que se comprometa o desempenho do produto. Essa tendência foi também observada na bateria de $\mathrm{Ni}-\mathrm{Cd}$ [26].

Tabela 2: Percentual médio $(\mathrm{m} / \mathrm{m})$ de Ni e Co nas baterias de Ni-MH em relação ao produto original antes da desmontagem* .

\begin{tabular}{ccc}
\hline Marca & $\% \mathrm{Ni}$ & $\mathrm{Co}$ \\
\hline $\mathrm{A}$ & $12,4 \pm 1,3$ & $1,7 \pm 0,1$ \\
$\mathrm{~B}$ & $11,1 \pm 0,7$ & $1,5 \pm 0,1$ \\
$\mathrm{C}$ & $12,6 \pm 1,8$ & $1,7 \pm 0,2$ \\
$\mathrm{D}$ & $10,7 \pm 1,4$ & $1,4 \pm 0,1$ \\
\hline
\end{tabular}

* valores expressos em intervalo de confiança a $95 \%$

Além da presença de níquel e de cobalto, a FRX acusou a existência de outros doze elementos: alumínio, potássio, manganês, ferro, sódio, zinco, fósforo, cálcio, ítrio, lantânio, cério e praseodímio. A Tabela 3 resume os percentuais $(\mathrm{m} / \mathrm{m})$ médios dos metais identificados. Observa-se que a participação dos lantanídios (em conjunto) é muito elevada, superando largamente a dosagem de cobalto verificada para essas baterias (Tabela 2), e também há uma importante quantidade de ferro presente. Sódio e potássio provêm do eletrólito $(\mathrm{NaOH}+\mathrm{KOH})$ utilizado na pasta eletrolítica. $\mathrm{Na}$ literatura, somente o $\mathrm{KOH}$ é mencionado como a base forte empregada na formulação em baterias de Ni-MH (ao contrário do que se sucede com as baterias de Ni-Cd [2]]). Todos os metais mencionados na Tabela 3, exceto o cálcio, já foram identificados nessa bateria $[$ ], 27] 
Tabela 3: Percentuais médios $(\mathrm{m} / \mathrm{m})$ dos metais identificados na lixívia de $\mathrm{Ni}-\mathrm{MH}$ em relação à bateria original ${ }^{*}$.

\begin{tabular}{cc}
\hline Elemento & Percentual \\
\hline $\mathrm{Fe}$ & $14,5 \pm 2,0$ \\
$\mathrm{~K}$ & $2,4 \pm 0,2$ \\
$\mathrm{Na}$ & $3,7 \pm 0,6$ \\
$\mathrm{Ca}$ & $0,7 \pm 0,2$ \\
$\mathrm{Mn}$ & $3,2 \pm 1,0$ \\
$\mathrm{Al}$ & $0,7 \pm 0,1$ \\
$\mathrm{P}$ & $0,6 \pm 0,1$ \\
$\mathrm{Zn}$ & $1,8 \pm 0,5$ \\
$\mathrm{Y}$ & $0,2 \pm 0,1$ \\
$\mathrm{La}$ & $6,3 \pm 0,3$ \\
$\mathrm{Ce}$ & $5,8 \pm 0,4$ \\
$\mathrm{Pr}$ & $0,7 \pm 0,1$ \\
\hline
\end{tabular}

* valores expressos em intervalo de confiança a $95 \%$

\subsection{Separação do Cobalto do Níquel em Meio Ácido}

Na solução de partida a acidez livre média foi de $6,5 \pm 0,3 \mathrm{~mol} \mathrm{~L}^{-1}$, e as concentrações de $\mathrm{Ni}^{2+}$ e de $\mathrm{Co}^{2+}$ estão na faixa $19,6 \pm 1,9$ e $2,0 \pm 0,5 \mathrm{~g} \mathrm{~L}^{-1}$, respectivamente.

Ao se adicionar solução de $\mathrm{NaOH}$ para ajuste do $\mathrm{pH}$ em 2, a solução passou às seguintes concentrações: $\mathrm{Ni}^{2+}, 18,7 \pm 1,6 \mathrm{~g} \mathrm{~L}^{-1}$, e $\mathrm{Co}^{2+}, 1,5 \pm 0,3 \mathrm{~g} \mathrm{~L}^{-1}$. No ajuste para $\mathrm{pH} 3$, as concentrações eram: $\mathrm{Ni}^{2+}, 17,1 \pm 1,3 \mathrm{~g} \mathrm{~L}^{-1}, \mathrm{e} \mathrm{Co}^{2+}, 1,4 \pm 0,3 \mathrm{~g} \mathrm{~L}^{-1}$. Em pH em 5, houve a formação de precipitado, cuja análise por FRX mostrou ser composto basicamente de metais trivalentes (hidróxidos de Fe, Al, Y e lantanídios), sendo isento de Co e Ni. Nesse $\mathrm{pH}$ as concentrações medidas eram: $\mathrm{Ni}^{2+}, 15,8 \pm 1,4 \mathrm{~g} \mathrm{~L}^{-1}$, e Co${ }^{2+}, 1,3 \pm 0,3 \mathrm{~g} \mathrm{~L}^{-1}$.

Com base nos cálculos dos valores do coeficiente de distribuição (D) para as extrações em pH 2, 3 e 5 para os extratantes D2EHPA, EHPA e Cyanex 272 (50\% vol/vol em querosene), observou-se que as separações em pH 2, 3 e 5 não foram eficientes em nenhum caso, isto é, a extração do cobalto e do níquel tiveram um baixo rendimento $(<10 \% \mathrm{~m} / \mathrm{m})$. Isso foi verificado por meio dos valores de $\mathrm{D}$ muito próximos de zero (inferior a $0,2 \mathrm{em}$ todos os casos). Isso contraria os resultados obtidos em meio sulfúrico [ $\underline{10}, \underline{18}, \underline{22}$, 28] e clorídrico [1, 28]. Nesses casos, a acidez livre era maior ( $\mathrm{pH}$ na faixa de $0-2)$, a massa de amostra dissolvida era menor, e em alguns casos a temperatura do processo de extração era mais elevada [18].

\subsection{Separação do Cobalto do Níquel em Meio Fracamente Alcalino}

No ajuste do pH até 7,2 houve a formação de um precipitado que foi isolado. Os dados de FRX indicam que todos os elementos trivalentes (lantanídios, Y, Fe e Al) estão nesse precipitado como hidróxidos. Metais divalentes como $\mathrm{Mn}, \mathrm{Zn} \mathrm{Ni}$ e Co não foram precipitados nestas condições, estando presentes na solução, cujas concentrações de $\mathrm{Ni}^{2+}$ e de $\mathrm{Co}^{2+}$ eram, respectivamente, $18,4 \pm 1,5 \mathrm{~g} \mathrm{~L}^{-1} \mathrm{e} 1,5 \pm 0,4 \mathrm{~g} \mathrm{~L}^{-1}$.

A Tabela 4 ilustra os dados de extração de Co e de $\mathrm{Ni}$ com os extratantes a $50 \% \mathrm{vol} / \mathrm{vol}$ em querosene. Os melhores resultados foram obtidos com Cyanex 272. Tanto o EHPA, quanto o D2EHPA não extraíram o níquel; o extratante EHPA extraiu algum cobalto, mas para um maior rendimento em recuperação, seria necessária uma segunda etapa de extração. O coeficiente de distribuição do cobalto com EHPA tem um valor muito baixo, comparado ao do Cyanex 272. Com esses resultados foi possível escolher este último como extratante para um estudo aprofundado de separação de cobalto do níquel em pH 7,2.

Tabela 4: Valores dos coeficientes de distribuição (D) para a extração do Ni e do Co em lixívia de Ni-MH em pH 7,2 utilizando EHPA, D2EHPA e Cyanex 272 a 50\% em querosene $\left(\left[\mathrm{Ni}^{2+}\right]=18,4 \pm 1,5 \mathrm{~g} \mathrm{~L}^{-1} ;\left[\mathrm{Co}^{2+}\right]=1,5 \pm 0,4 \mathrm{~g} \mathrm{~L}^{-1}\right)$.

\begin{tabular}{cccc}
\hline Extratante & $\mathbf{D}_{\mathrm{Ni}}$ & $\mathbf{D}_{\mathbf{C o}}$ & $\mathbf{D}_{\mathbf{C o}} / \mathbf{D}_{\mathbf{N i}}$ \\
\hline D2EHPA & $<0,1$ & $0,2 \pm 0,1$ & $>1$ \\
EHPA & $0,06 \pm 0,05$ & $2,5 \pm 0,7$ & $4,2 \times 10^{1}$ \\
Cyanex 272 & $0,2 \pm 0,1$ & $59,6 \pm 0,1$ & $3,0 \times 10^{2}$ \\
\hline
\end{tabular}

Nesse estudo variou-se a concentração do extratante em querosene ( $5-50 \% \mathrm{vol} / \mathrm{vol})$. A Tabela 5 mostra os valores dos coeficientes de distribuição para as extrações realizadas. As extrações foram mais 
eficientes quando se empregaram soluções diluídas ( $5 \%$ vol), ou seja, o processo é mais seletivo para o íon $\mathrm{Co}^{2+}$ quando o extratante está em baixa concentração para a remoção de um elemento em concentração bastante inferior ao do elemento mais abundante $\left(\mathrm{Ni}^{2+}\right)$.

Tabela 5: Valores dos coeficientes de distribuição (D) para as extrações de Ni e de Co da lixívia de Ni-MH em $\mathrm{pH}$ 7,2 variando a concentração de Cyanex $272 \mathrm{em}$ querosene

$$
\left(\left[\mathrm{Ni}^{2+}\right]=18,4 \pm 1,5 \mathrm{~g} \mathrm{~L}^{-1} ;\left[\mathrm{Co}^{2+}\right]=1,5 \pm 0,4 \mathrm{~g} \mathrm{~L}^{-1}\right) \text {. }
$$

\begin{tabular}{ccc}
\hline Concentração (vol/vol) & $\mathbf{D}_{\mathbf{N i}}$ & $\mathbf{D}_{\mathbf{C o}}$ \\
\hline $5 \%$ & $0,01 \pm 0,01$ & $113,1 \pm 0,5$ \\
$10 \%$ & $0,05 \pm 0,02$ & $99,4 \pm 0,3$ \\
$20 \%$ & $0,2 \pm 0,01$ & $89,0 \pm 0,2$ \\
$30 \%$ & $0,2 \pm 0,03$ & $75,2 \pm 0,1$ \\
$40 \%$ & $0,2 \pm 0,05$ & $65,2 \pm 0,1$ \\
$50 \%$ & $0,2 \pm 0,05$ & $59,6 \pm 0,1$ \\
\hline
\end{tabular}

A partir desse resultado, retomou-se o estudo da extração em meio ácido, variando-se a concentração de Cyanex 272 em querosene (5-50\% vol/vol). Os dados estão na Tabela 6, e são expressos em $\% \mathrm{~m} / \mathrm{m}$ de elemento removido da fase aquosa ácida. De acordo com os resultados dessa Tabela foi possível observar a extração mais efetiva do cobalto em $\mathrm{pH} 7,2$ empregando solução do extratante a $5 \%$ em querosene. Quando se aumentou a concentração do extratante a separação dos metais não foi tão eficiente, pois parte do níquel foi extraído juntamente com o cobalto, e o coeficiente de distribuição deste último diminuiu, tornando a extração menos seletiva e perdendo sua própria objetividade. A extração do cobalto em meio aproximadamente neutro é diferente dos processos em meio ácido relatados na literatura, e tem a vantagem de ser quantitativa $(>99 \% \mathrm{~m} / \mathrm{m}$ - resultado comparável ou superior aos valores relatados na literatura - 96-98\% m/m), e realizada em um único estágio, ao contrário do que se sucede na maioria dos estudos da literatura $[\underline{1}, \underline{18}]$ (dois ou mais estágios).

Tabela 6: Comparação entre os percentuais extraídos de Ni e de Co a partir de uma lixívia de Ni-MH em diversos $\mathrm{pH}^{\prime}$ s com Cyanex 272 dissolvido em querosene.

\begin{tabular}{|c|c|c|c|}
\hline Concentração (\% vol/vol) & pH & \%m/m de Ni extraído & \%m/m de Co extraído \\
\hline \multirow{4}{*}{$5 \%$} & 2 & $0,5 \pm 0,1$ & $0,7 \pm 0,1$ \\
\hline & 3 & $0,2 \pm 0,1$ & $1,0 \pm 0,1$ \\
\hline & 5 & $0,2 \pm 0,2$ & $1,3 \pm 0,1$ \\
\hline & 7,2 & $<0,1$ & $99,1 \pm 0,9$ \\
\hline \multirow{4}{*}{$10 \%$} & 2 & $0,8 \pm 0,2$ & $1,0 \pm 0,5$ \\
\hline & 3 & $0,5 \pm 0,2$ & $1,2 \pm 0,2$ \\
\hline & 5 & $0,9 \pm 0,1$ & $1,2 \pm 0,3$ \\
\hline & 7,2 & $0,6 \pm 0,1$ & $99,0 \pm 0,8$ \\
\hline \multirow{4}{*}{$20 \%$} & 2 & $0,4 \pm 0,3$ & $1,3 \pm 0,5$ \\
\hline & 3 & $0,5 \pm 0,1$ & $1,4 \pm 0,5$ \\
\hline & 5 & $0,7 \pm 0,4$ & $1,1 \pm 0,4$ \\
\hline & 7,2 & $1,2 \pm 0,5$ & $98,8 \pm 0,9$ \\
\hline \multirow{4}{*}{$30 \%$} & 2 & $0,9 \pm 0,1$ & $1,3 \pm 0,5$ \\
\hline & 3 & $0,4 \pm 0,2$ & $1,5 \pm 0,5$ \\
\hline & 5 & $0,8 \pm 0,2$ & $1,2 \pm 0,3$ \\
\hline & 7,2 & $1,1 \pm 0,3$ & $98,8 \pm 0,9$ \\
\hline \multirow{4}{*}{$40 \%$} & 2 & $0,9 \pm 0,5$ & $1,2 \pm 0,5$ \\
\hline & 3 & $0,4 \pm 0,1$ & $2,0 \pm 0,2$ \\
\hline & 5 & $0,8 \pm 0,2$ & $1,8 \pm 0,3$ \\
\hline & 7,2 & $1,1 \pm 0,3$ & $98,7 \pm 0,9$ \\
\hline \multirow{4}{*}{$50 \%$} & 2 & $0,4 \pm 0,1$ & $2,0 \pm 0,2$ \\
\hline & 3 & $0,5 \pm 0,1$ & $2,7 \pm 0,1$ \\
\hline & 5 & $0,5 \pm 0,2$ & $3,6 \pm 0,5$ \\
\hline & 7,2 & $1,1 \pm 0,5$ & $98,7 \pm 0,9$ \\
\hline
\end{tabular}




\subsection{Isolamento dos Lantanídios}

$\mathrm{O}$ interesse recai no precipitado bruto contendo esses elementos obtido ao se ajustar o $\mathrm{pH}$ a 7,2, pois é onde o cobalto foi extraído. A análise por FRX mostrou que este sólido era essencialmente composto de metais trivalentes: ferro, alumínio e lantanídios (o ferro compunha $54,8 \% \mathrm{~m} / \mathrm{m}$ deste precipitado, o alumínio $0,2 \%$, e os lantanídeos + ítrio em conjunto, $45 \%$ ). Fósforo foi também detectado, sugerindo a presença de fosfatos. Não foram detectados metais divalentes (manganês, cálcio, zinco, níquel e cobalto), que permaneceram em solução. Como a solução preparada para a extração do cobalto não continha os lantanídios (segundo os dados de FRX), fica evidente que este precipitado é a matéria-prima para o isolamento dos mesmos.

O procedimento, a rigor, deve ser encarado como de purificação a partir de um sólido bruto impuro. A coloração esverdeada do precipitado purificado de oxalatos de Y, La, Ce e Pr é devida a este último. Neste procedimento, o ferro, o fósforo e o alumínio não precipitam (da mesma forma, se estivessem presentes, o cobalto e o níquel não precipitariam nestas condições $[24,25])$.

A análise por FRX acusou um rendimento em isolamento dos lantanídios de 98,4 $\pm 0,7 \% \mathrm{~m} / \mathrm{m}$, classificando este procedimento como excelente para recuperação desses elementos, e este resultado é comparável àqueles relatados na literatura $(94-99 \% \mathrm{~m} / \mathrm{m}[\underline{1}, \underline{2}, \underline{10}])$. A recuperação de oxalatos é preferível a de fosfatos e sulfatos duplos por conta da facilidade de convertê-los em óxidos (precursores dos sais de lantanídios) e da ausência de outros metais ou espécies de eliminação mais difícil.

\subsection{Isolamento do Níquel}

O precipitado de cor verde-maçã contendo $\mathrm{Ni}(\mathrm{OH})_{2}$, obtido após a extração do cobalto (e a remoção de praticamente todos os metais trivalentes), foi analisado por FRX. Além do níquel, manganês, zinco, traços de alumínio, fósforo e cobalto não extraído foram identificados. O níquel perfaz cerca de $75 \% \mathrm{~m} / \mathrm{m}$ de todos os metais presentes. Uma primeira purificação foi efetuada neste sólido, através da adição de solução de $\mathrm{NaOH} 6 \mathrm{~mol} \mathrm{~L}^{-1}$ contendo $\mathrm{H}_{2} \mathrm{O}_{2}$ a $3 \% \mathrm{~m} / \mathrm{m}$ (para oxidar $\mathrm{Mn}(\mathrm{II})$ a $\mathrm{Mn}(\mathrm{IV})$ e dissolver o zinco e o alumínio), seguido de adição de $\mathrm{NH}_{4} \mathrm{OH}$ concentrado no sólido residual. Nessa solução amoniacal, o níquel perfaz mais de $98 \% \mathrm{~m} / \mathrm{m}$ dos metais dissolvidos e contém mais de $95 \% \mathrm{~m} / \mathrm{m}$ de todo o níquel presente na lixívia ácida original. O resíduo insolúvel contém manganês, fósforo e traços de cobalto. Outra possibilidade é a dissolução desse precipitado impuro em meio de ácido sulfúrico para extração do níquel, de acordo com sugestões já propostas na literatura $[\underline{29}, \underline{30}]$. Na continuidade desta pesquisa, estão sendo buscadas metodologias para o isolamento do níquel a partir de seu precipitado impuro.

\subsection{Gestão de Resíduos}

O processamento de uma bateria usada é complexo face ao fato de ser um produto composto por muitos materiais diferentes em natureza, cuja destinação final é diferente caso a caso. Assim, o separador polimérico e a carcaça externa plástica podem ser recicladas ou então incineradas para recuperação energética (recuperação quaternária) [31]. O invólucro de aço pode ser reciclado.

Os resíduos finais aquosos representam o principal desafio de gestão. As soluções finais precisam apresentar as seguintes características: pH entre 6 e 8, ausência de coloração e turbidez (sólidos em suspensão), caráter redox indiferente e concentração de metais pesados dentro das normas estabelecidas na resolução 357/05 do Conselho Nacional de Meio Ambiente (CONAMA) [르].

Após a precipitação dos sólidos contendo cobalto ou níquel, as soluções finais são próximas da neutralidade (ca. 8); a neutralização foi obtida adicionando-se $\mathrm{HCl} 6 \mathrm{~mol} \mathrm{~L}^{-1}$. Elas consistem essencialmente de soluções de cloreto de sódio, com menos de $50 \mathrm{ppm}$ de metais pesados $(\mathrm{Fe}+\mathrm{Mn}+\mathrm{Ni}+\mathrm{Co}+\mathrm{Zn})$. Embora sejam soluções incolores, com baixíssimos teores em metais pesados e de caráter redox indiferente, uma questão que se levanta é a alta salinidade desses efluentes devido ao emprego de ácido clorídrico concentrado na abertura e na reextração do cobalto.

A situação acima não encontra paralelo nos estudos realizados com os ácidos clorídrico e sulfúrico recentemente publicados, que não destacam a gestão dos resíduos de processo. Em comparação com este trabalho os estudos da literatura empregam ácidos diluídos (1-4 mol L-1), $\mathrm{pH}$ (acidez livre) entre 0 e 2, e no máximo $100 \mathrm{~g}$ de material por L de solução ácida (neste estudo, $150 \mathrm{~g} \mathrm{~L}^{-1}$ ). No caso específico do meio clorídrico $[1,10,21]$, o número de estágios sempre foi de dois ou mais. Por isso o volume de resíduo final aquoso gerado (20 mL g ${ }^{-1}$ componente interno processado) é inferior ao da literatura (até três vezes mais). A relação concentração de sal em relação ao volume de efluente final deve ponderada em vista de aspectos da legislação ambiental vigente, da eventual utilização dessa salmoura em algum processo e do custo local da água tratada. Uma solução ácida mais concentrada aumenta o custo do processo (material dos equipamentos mais caro) mas, para o mesmo volume, mais material pode ser processado (aumento de escala). Uma solução de lixívia mais diluída é menos corrosiva, mas exige maiores volumes de equipamento ou uma escala de 
trabalho mais reduzida. A seqüência desta pesquisa sugere a otimização do processo de abertura, isto é, a busca de condições experimentais mais seletivas para a dissolução dos componentes internos das baterias, com ênfase na redução da quantidade de ácido empregada na abertura do material.

Há uma segunda fonte de geração de efluentes finais: após a precipitação dos lantanídios. Neste caso, a solução ácida residual foi neutralizada com NaOH $6 \mathrm{~mol} \mathrm{~L}^{-1}$, levando à precipitação do alumínio, do ferro e de traços de lantanídios. A solução final consiste de uma mistura de oxalato e cloreto de sódio, de salinidade inferior à da outra solução final. O sólido pode servir como matéria-prima para co-processamento. A massa obtida é da ordem de $30 \mathrm{~g} \mathrm{~L}^{-1}$ de solução de ácida original, o que exige uma quantidade considerável de baterias processadas para se obter uma massa viável para esta destinação final.

\section{CONCLUSÕES}

A recuperação de elementos por extração com solventes é uma alternativa capaz de separar elementos de química muito semelhante (como $\mathrm{Ni}$ e $\mathrm{Co}$ ), com a vantagem de gerar menos resíduos finais face à possibilidade de reutilização desses solventes, e a não adição de reagentes tóxicos (como sulfetos) para se conseguir a mesma separação obtida por meios convencionais. Após dissolução da bateria de Ni-MH em $\mathrm{HCl}$, o cobalto foi melhor separado do níquel mediante o emprego do extratante Cyanex $272 \quad(5 \%$ vol. em querosene) em pH 7,2, com rendimento de $\sim 99 \% \mathrm{~m} / \mathrm{m}$. A química bem diferenciada dos lantanídios permitiu a sua separação de outros metais trivalentes por meio de tratamento do precipitado impuro com $\mathrm{HCl}$ (acidez livre entre 1-2 $\mathrm{mol} \mathrm{L}^{-1}$ ), seguido de adição de solução de oxalato de amônio (precipitação seletiva) com alto rendimento e pureza elevada $(>98 \% \mathrm{~m} / \mathrm{m})$. A rota hidrometalúrgica de processamento de materiais usados demonstrou a versatilidade e a flexibilidade que os processos pirometalúrgicos não apresentam.

A análise da composição das baterias mais modernas (fabricadas a partir de 2002) mostra uma tendência à redução dos teores de níquel em relação aos valores normalmente tabelados na literatura, indicativo de uma mudança de tecnologia que reduza a demanda deste elemento tóxico; porém, numa projeção para o futuro, a melhor alternativa será a substituição tanto quanto possível das atuais tecnologias de dispositivos recarregáveis contendo níquel, cádmio e outros elementos perigosos por tecnologias mais compatíveis com o meio ambiente e a vida. As baterias de íon-lítio, de reciclagem mais fácil que os modelos convencionais [33] , são uma resposta a essa tendência de evolução tecnológica no mundo da energia portátil.

\section{AGRADECIMENTOS}

À Divisão de Química e Materiais Nucleares do Instituto de Engenharia Nuclear pelas análises químicas necessárias a este trabalho. Ana Paula M. G. Barandas agradece à FAPERJ e à CAPES a concessão de bolsa de M.Sc. Ao CNPq pelo auxílio financeiro.

\section{BIBLIOGRAFIA}

[1] ZHANG, P., YOKOYAMA, T., ITABASHI, O., et al., "Hydrometallurgical Process for Recovery of Metal Values from Spent nickel-metal Hydride Secondary Batteries”, Hydrometallurgy, v. 50, n. 1, pp. 61-75, Sep. 1998.

[2] YOSHITA, T., ONO, H., SHUAI, R., "Recycling of Used Ni-MH Rechargeable Batteries", In: Proceedings of the Third International Symposium on Recycling of Metals and Engineered Materials, pp. 145-152, Warrendale, May 1995.

[3] WRONSKI, Z. S., "Materials for Rechargeable Batteries and Clean Hydrogen Energy Sources", Intern. Materials Review, v. 46, n. 1, pp. 1-49, Mar. 2001.

[4] ASSOCIAÇÃO BRASILEIRA DA INDÚSTRIA ELÉTRICA E ELETRÔNICA, http://www.tec.abinee.org.br/arquivos/s907.pdf, Acessado em setembro de 2005.

[5] RUETSCHI, P., MELI, F., DESILVESTRO, J., "Nickel-metal Hydride Batteries. The Preferred Batteries of the Future”, Journal of Power Sources, v. 57, n. 1-2, pp. 85-91, Sep.-Dec. 1995.

[6] LICHTENBERG, F., "Development of $\mathrm{AB}_{5}$ type Hydrogen Storage Alloys with low Co Content for Rechargeable Ni-MH Batteries with Respect to Electric Vehicle Applications”, Journal of Alloys and Compounds, v. 253-254, pp. 570-573, May 1997. 
[7] RYDH, C. J., SVARD, B., "Impact on Global Metal Flows Arising from the use of Portable Rechargeable Batteries", Science of the Total Environment, v. 302, n.1-2, pp. 167-184, Jan. 2003.

[8] PUTOIS, F., “Market for nickel-cadmium batteries”, Journal Power Sources, v. 57, n. 1-2, pp. 67-70, Sep.-Dec. 1995.

[9] EUROPEAN PORTABLE BATTERY ASSOCIATION, http://www.epba-europe.org, acessado em novembro de 2005

[10] ZHANG, P., YOKOYAMA, T., ITABASHI, O. et al., "Recovery of Metal Values from Spent nickelmetal Hydride Rechargeable Batteries”, Journal Power Sources, v. 77, n. 2, pp. 116-122, Feb. 1999.

[11] LUPI, C., PILONE, D., "Ni-MH Spent Batteries: A Raw Material to Produce Ni-Co alloys”, Waste Management, v. 22, n. 8, pp. 871-874, Dec. 2002.

[12] ROSKILL INFORMATION SERVICES, http://www.roskill.com/reports/cobalt, acessado em dezembro de 2005.

[13] COSTA, M., DAVIDSON, T.L., CHEN, H. et al., "Nickel Carcinogenesis: Epigenetics and Hypoxia Signaling”, Mutation Research, v. 592, n. 1-2, pp. 79-88, Dec. 2005.

[14] REIDLER, N.M.V.L., "Resíduos Gerados por Pilhas e Baterias Usadas: Uma Avaliação da Situação Brasileira 1999-2001”, Dissertação de M. Sc., Faculdade de Saúde Pública/USP, São Paulo, SP, Brasil, 2002.

[15] FURTADO, J.S., Baterias Esgotadas: Legislações \& Gestão, Ministério do Meio Ambiente, 2004.

[16] LEI N ${ }^{\mathrm{O}} 3.415,29 / 05 / 2000$, DIÁRIO OFICIAL DO ESTADO DO RIO DE JANEIRO, 09/06/2000.

[17] LYMAN, J.W., PALMER, G.R., "Process for Treating nickel-metal Hydride Battery Scrap", Patente Americana, 5.429.887, Jul. 1995.

[18] MATUANO, D.P., ELIAS, R.C.A., DORELLA, G. et al., "Analysis of a Hydrometallurgical Route to Recover Metals from Spent NiCd and NiMH Mobile Batteries", In: Proceedings of the XIIIth International Conference on Heavy Metals in Environment, pp. 1415-1418, Rio de Janeiro, Jun. 2005.

[19] MANTUANO, D.P., "Desenvolvimento de Uma Rota Processual Hidrometalúrgica Para a Recuperação de Metais Provenientes de Baterias de Celular Descarregadas", Dissertação de M. Sc., EE/DEQ/UFMG, Belo Horizonte, MG, Brasil, 2005.

[20] GALÁN, B., SAN ROMÁN, F., IRABIEN, A. et al., "Viability of the Separation of Cd from Highly Concentrated Ni-Cd Mixtures by non-dispersive Solvent Extraction", Chemical Engineering Journal, v. 70, n. 3, pp. 237-243, Set. 1998.

[21] LYMAN, J. W., PALMER, G. R., "Hydrometallurgical Treatment of Nickel-Metal Hydride Battery Electrodes", In: Proceedings of the Third International Symposium on Recycling of Metals and Engineered Materials, pp. 131-144, Warrendale, May 1995.

[22] AHN, J. G., PARK, K. H., SOHN, J. S., "Solvent Extraction Separation of Co, Mn and Zn from Ni-rich Leaching Solution by Na-PC88A”, Materials Transactions, v. 43, n. 8, pp. 2069-2072, Jun. 2002.

[23] PIETRElli, L., BELlOMO, B., FONTANA, D. et al., "Rare Earths Recovery from NiMH Spent Batteries”, Hydrometallurgy, v. 66, n. 1-3, pp. 135-141, Oct. 2002.

[24] VOGEL, A.I., Análise Química Quantitativa, ed. 5, Rio de Janeiro, Livros Técnicos e Científicos, 1992.

[25] ABRÃO, A., Química e Tecnologia das Terras Raras, ed. 1, Rio de Janeiro, CETEM/CNPq, 1994. 
[26] BARANDAS, A.P.M.G., VALVERDE JR, I.M., AFONSO, J.C., et al., "Recuperação de Cádmio de Baterias Níquel-Cádmio Via Extração Seletiva com Tributilfosfato (TBP)”, Quim Nova, submetido. http://www.rbrc.org/licensee/index.html, acessado em novembro de 2005.

[28] TAIT, B.K., "Cobalt-nickel Separation: The Extraction of cobalt(II) and nickel(II) by Cyanex 301, Cyanex 302 and Cyanex 272”, Hydrometallurgy, v. 32. n. 3, pp. 365-372, Apr. 1993.

[29] CAlligaro, L., MANTOVANI, A., BELlUCO, U. et al., "Solvent Extraction of copper(II), nickel(II), cobalt(II), zinc(II), and iron(Ill) by High Molecular Weight Hydroxyoximes", Polvhedron, v. 2, n. 11, pp. 1189-1193, Nov. 1983.

[30] NOGUEIRA, C.A., DELMAS, F., "New Flowsheet for the Recovery of Cadmium, Cobalt and Nickel from Spent Ni-Cd Batteries by Solvent Extraction”, Hydrometallurgy, v. 52, n. 3, pp. 267-287, Jun. 1999.

[31] MANO, E.B., BONELLI, C.M.C., “A Reciclagem de Plásticos Pós-consumidos”, Revista de Química Industrial, v. 698, pp. 18-22, Out.-Dez. 1994.

[32] RESOLUÇÃO N. 357 DO CONSELHO NACIONAL DE MEIO AMBIENTE (CONAMA), 18/03/2005, Diário Oficial da União em 19/03/2005.

[33] BROUSSEly, M., ARCHDAlE, G., "Li-ion Batteries and Portable Power Source Prospects for the next 5-10 years”, Journal Power Sources, v. 136, n. 2, pp. 386-394, Oct. 2004. 